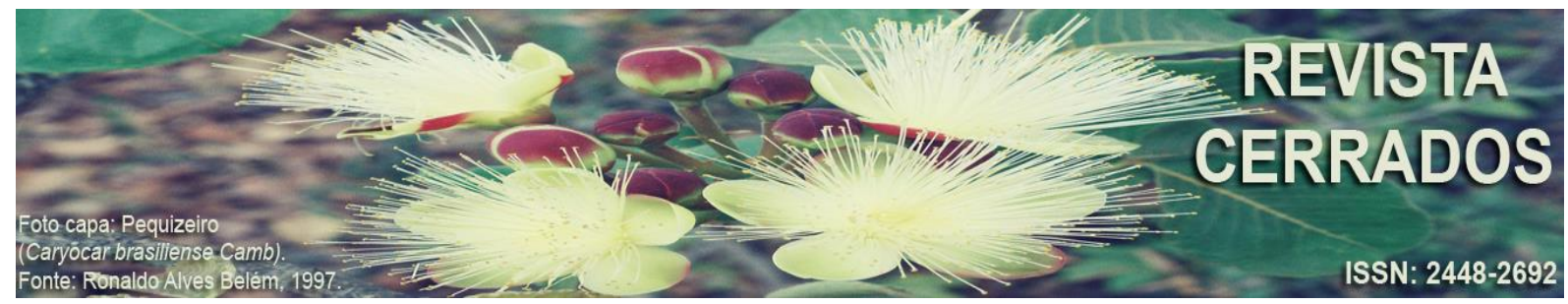

\title{
A QUESTÃO AGRÁRIA NO TERRITÓRIO RURAL DO BOLSÃO/MS: algumas aproximações ${ }^{1}$
}

\section{THE AGRARIAN QUESTION IN TERRITÓRIO RURAL DO BOLSÃO/MS: some approaches}

\section{LA CUESTIÓN AGRARIA EN EL TERRITORIO RURAL DEL BOLSÃO/MS: algunas aproximación}

\author{
Danilo Souza Melo \\ Universidade Federal de Mato Grosso do Sul - UFMS \\ E-mail: <danilosouza.geo@ hotmail.com> \\ Mariele de Oliveira Silva \\ Universidade Estadual de Londrina - UEL \\ E-mail: <mosgeolice@gmail.com>
}

\begin{abstract}
Resumo
O Território Rural do Bolsão/MS, a partir do ano de 2006, presencia nova reconcentração fundiária, por meio da expansão territorial do complexo eucalipto-celulose. Circunstância que tem ocasionado visíveis transformações territoriais, especialmente nas áreas circunvizinhas às empresas localizadas próximos aos projetos de reforma agrária. Nessa perspectiva, objetivamos com esta pesquisa: abordar a territorialização do complexo eucalipto-celulose e as estratégias de (re)criação camponesa nos projetos de assentamento da Reforma Agrária, com o intuito de apreender algumas aproximações a respeito da atual questão agrária no Território. Como metodologia de análise, recorremos à: revisão bibliográfica de obras que tratam da questão agrária; como procedimento de coleta de dados: ao trabalho de campo e uso de fontes orais; e como técnica de pesquisa: pela aplicação de entrevistas aleatórias. Por meio desse trabalho percebemos que houve a valorização do preço das terras e a inserção de programas sociais realizados pelas empresas nos assentamentos a partir da expansão do

\footnotetext{
1 Este trabalho é resultado do Projeto de Pesquisa: Território Rural do Bolsão/MS: implementação, viabilidades e contradições. Coordenado pelo Prof. Dr. Sedeval Nardoque. Neste trabalho, foram utilizados resultados de trabalhos de campo da pesquisa "A (re)criação do campesinato em Cáceres/MT e no contexto de expansão territorial do agronegócio em Três Lagoas e Selvíria em Mato Grosso do Sul" de autoria de Mariele de Oliveira Silva.
} 
complexo eucalipto-celulose, ocasionando respectivamente a paralisação e privatização da política de Reforma Agrária. Em contrapartida há nos territórios da Reforma Agrária a resistência inovada do campesinato a partir da apropriação tanto dos mercados institucionais PAA e o PNAE quanto pelo fortalecimento dos grupos informais de comércio justo.

Palavras-chave: Questão Agrária; Complexo eucalipto-celulose; Cerrado; (Re)criação camponesa; Território Rural do Bolsão/MS.

\begin{abstract}
The Rural Territory of Bolsão/ MS, from the year 2006, witnesses new land reconcentration through the territorial expansion of eucalyptus-cellulose complex. Circumstance that has caused visible territorial transformations, especially in the surrounding areas of companies located next to agrarian reform projects. In this perspective, we aim with this research: address the territorialization of the eucalyptus-cellulose complex and strategies of (re)creation of peasant settlement projects of agrarian reform, in order to grasp some approaches regarding the current agrarian question in the Territory. As analysis methodology, we used the literature review of works that deal with the land question; as data collection procedure: the field work and the use of oral sources; and as research technique: for the application of random interviews. Through this work we realized that there was the exploitation of land prices and the insertion of social programs undertaken by companies in the settlements from the expansion of the eucalyptus-pulp, causing respectively the paralysis and privatization of land reform policy.
\end{abstract}

Keywords: Agrarian Question; Eucalyptus-cellulose complex; Land reconcentration; Cerrado; Peasant (re)creation; Território Rural do Bolsão/MS.

\title{
Resumen
}

Lo Território Rural do Bolsão/MS, la partir del año de 2006, presencia nueva reconcentración agraria, por medio de la expansión territorial del complejo eucalipto-celulosa. Circunstancia que tiene ocasionado visibles transformaciones territoriais, especialmente en las áreas alrededores de las empresas localizadas cercana a los projectos de reforma agraria. En esta perspectiva, objetivamos con esta investigación: abordar la territorialización del complejo eucalipto-celulosa y las estrategias de (re)creacíon campesina en los projectos de asentamiento de la Reforma Agraria, con la meta de aprehender algunas aproximaciones la respeto de la actual cuestión agraria en lo Território. Como metodología de análisis, recorremos a: revisión bibliográfica de obras que tratam de la cuestión agraria; como procedimiento de colecta de datos: al trabajo de campo y uso de fuentes orais; y como técnica de investigación: por la aplicación de entrevistas aleatorias. A través de este trabajo nos dimos cuenta de que era la explotación de los precios de la tierra y la inserción de programas sociales emprendidas por las empresas en los asentamientos de la expansión de la pasta de eucalipto respectivamente, causando la parálisis y la privatización de la política de reforma agraria. 
Palabras-clave: Cuestión agrária; Complejo eucalipto-celulosa; (Re)creacíon campesina; Cerrado; Território Rural do Bolsão/MS.

\section{INTRODUÇÃO}

O Estado brasileiro, nos últimos anos (desde 2003), vem utilizando novas estratégias de abordagem para implantar políticas de combate à pobreza, principalmente no campo. Visando a inclusão produtiva e o fortalecimento da agricultura familiar (BRASIL, 2015), o Estado adotou estratégias para promover o desenvolvimento rural em nova perspectiva e escala de atuação, "descentralizando" as decisões sobre as políticas e uso dos recursos, como afirma Corrêa (2009, p.23). Essas medidas objetivam promover o desenvolvimento local (Território Rural $^{2}$ ) por meio da articulação dos atores sociais locais ${ }^{3}$, trata-se:

[...] de uma visão integradora de espaços, atores sociais, mercados e políticas públicas de intervenção, por meio da qual se pretende alcançar: a geração de riquezas com equidade; o respeito à diversidade; a solidariedade; a justiça social; a inclusão social (BRASIL, 2005, p.08).

No entanto, Gómez (2006) indica que este tipo de descentralização passa a responsabilidade do estado de pobreza e desigualdade para o camponês, isentando o Estado. Assim,

O aumento da importância da escala local (do Território Rural), na implementação da política de desenvolvimento rural, tem muito a ver com uma narrativa que insiste na redução das funções do Estado, em certas áreas, e na co-responsabilização dos pobres com sua pobreza e no fracasso das políticas que tentam aliviá-la. Uma narrativa afinada com os objetivos da globalização capitalista neoliberal (GÓMEZ, 2006, p. 406).

Nesse sentido, Fabrini (2011) acrescenta que,

\footnotetext{
${ }^{2}$ Os Territórios Rurais são “[...] formados por aglutinação de municípios de forte perfil rural, geralmente contínuos e pertencentes a um mesmo estado da Federação (existem poucas exceções a essas duas regras)". (GOMEZ, 2006, p.90).

${ }^{3}$ Termo utilizado pelo Estado nos documentos oficiais. Entendemos que no bojo dos "atores sociais locais" estão os camponeses assentados e camponeses tradicionais e as comunidades tradicionais, como pescadores, quilombolas e indígenas.
} 
A transferência de poder para a sociedade civil organizada pode se comunicar com o ideário liberal, pois os próprios sujeitos, investidos de poder e controle sobre o espaço, se encarregam de resolver seus problemas, forjando uma desobrigação estatal. Dessa forma, a dimensão territorial pode se vincular a um antiestatismo em nome do poder à sociedade civil organizada e, por isso, empresários, órgão multilaterais, governos e intelectuais, dentre outros, aprovam tal dimensão (FABRINI, 2001, p.98).

Podemos citar como resultado da política pública brasileira de desenvolvimento territorial, o Território Rural do Bolsão (MS), criado em 2013. Localizado na região Leste de Mato Grosso do Sul (mapa 1), esse território é composto por oito municípios: Três Lagoas, Água Clara, Selvíria, Paranaíba, Aparecida do Taboado, Inocência, Cassilândia e Chapadão do Sul.

Mapa 1- Mato Grosso do Sul: Território Rural do Bolsão

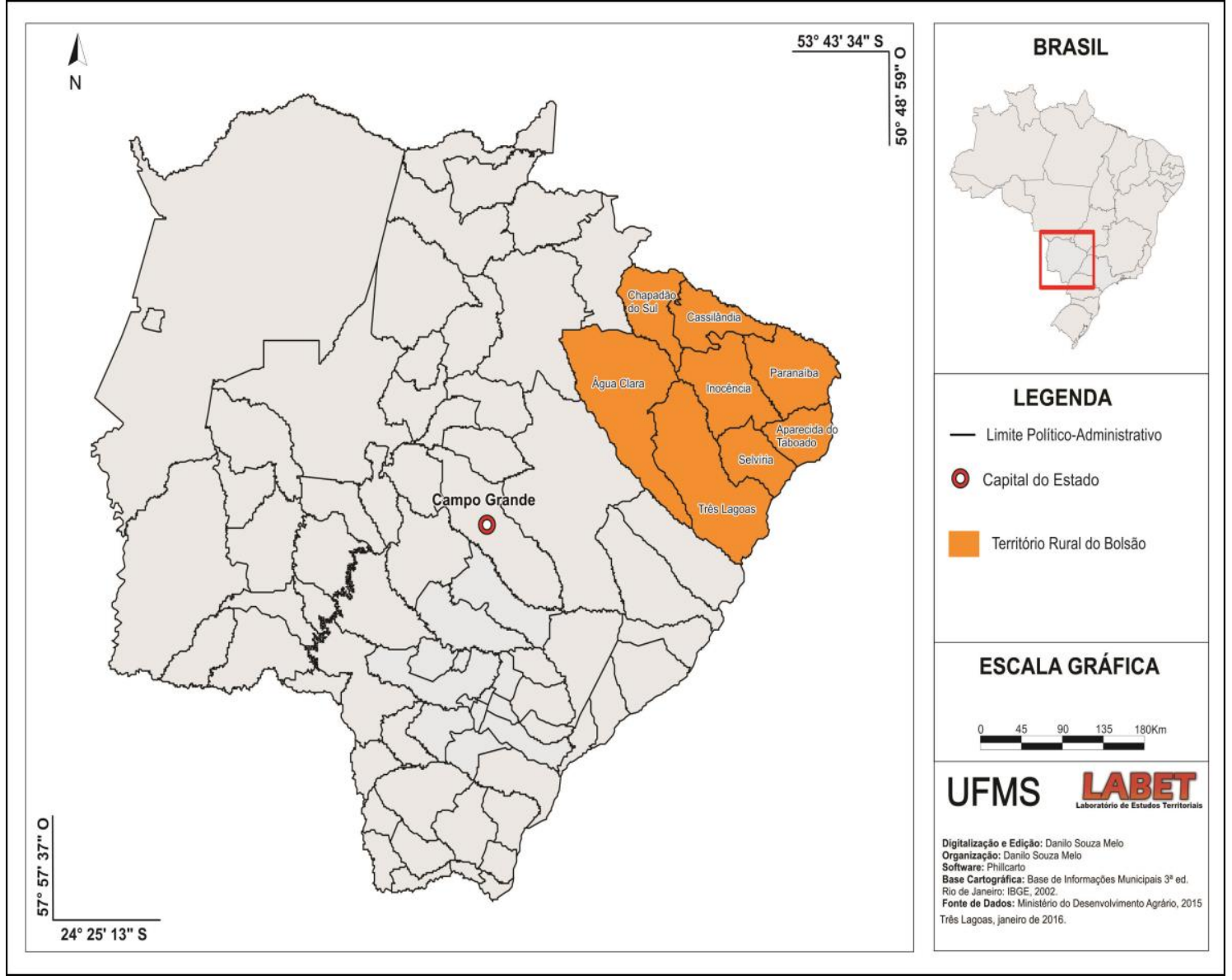

Fonte: MDA, 2015.

Alguns desses municípios possuíam economia baseada, principalmente, na atividade pecuária de bovinocultura de corte com forte concentração fundiária. Porém, desde 2006, esse Território presencia nova reconcentração fundiária sob a égide do latifúndio monocultor, representado pela expansão territorial do monocultivo do eucalipto, com a 
escolha do município de Três Lagoas, para ser a sede da maior fábrica de celulose e papel do Brasil, conhecida como Horizonte - controlada pela Fibria. Concomitantemente, no ano de 2010, para outra empresa de celulose e papel, representada pelo grupo JBS e MCL Empreendimentos, a Eldorado Brasil.

O Território do Bolsão também está localizado no Centro-Oeste Brasileiro e possui como bioma o Cerrado. Este, por sua vez, vem sendo devastado pelo desenvolvimento da agricultura capitalista. Desta maneira;

O cerrado brasileiro, com sua enorme diversidade biológica e cultural, tem se transformado numa área de expansão desses grandes latifúndios produtivos, pelas enormes vantagens que oferece, seja pela riqueza hídrica que abriga, seja pela topografia plana de suas chapadas e de seus chapadões. Avalia-se que $70 \%$ da área das chapadas já esteja ocupada por esse tipo de empresa, seja com cultivo de grãos, algodão ou de monoculturas de plantação de madeira (eucaliptos e pinus) (PORTO GONÇALVES, 2006, p.250).

No Território do Bolsão o desenvolvimento da agricultura capitalista paradoxalmente dificulta a efetivação da Reforma Agrária, pois as duas empresas escolheram, inicialmente, como áreas prioritárias para o plantio, as áreas ligadas anteriormente às atividades de pecuária extensiva, que estão localizadas no entorno de alguns projetos de Reforma Agrária nos municípios de Três Lagoas e Selvíria. Essa situação tem provocado:

- O cerceamento dos Projetos de Assentamentos, provocando o aumento do ataque dos animais nas lavouras e hortas em busca de alimentos e o aumento do trabalho acessório dos assentados;

- Estado de paralisação da política de Reforma Agrária: valorização no preço das terras, pois no Brasil os programas de reforma agrária são realizados via financiamento de compra e venda de terras, desapropriação;

- Processo de privatização da Reforma Agrária: inserção de programas sociais realizados pelas empresas nos assentamentos, para a obtenção de certificações para a venda da produção (celulose) nos mercados estrangeiros, assumindo o papel do Estado.

Essas condições têm proposto novas abordagens a respeito da questão agrária no Território Rural do Bolsão/MS. Nessa perspectiva, esse artigo objetiva abordar algumas aproximações a respeito das novas reformulações da questão agrária, a partir dos desafios suscitado com a territorialização do complexo eucalipto-celulose e as estratégias de (re)criação camponesa nos projetos de assentamento da Reforma Agrária. 
Fundamentalmente balizado por trabalhos de campo no Território junto ao Núcleo de Extensão em Desenvolvimento Territorial (NEDET) do Bolsão (MS), essa metodologia foi essencial na descoberta da diversidade camponesa registrada principalmente em fotos e entrevistas. Utilizamos os dados estatísticos do Instituto Brasileiro de Geografia e Estatística (IBGE) e Instituto Nacional de Colonização e Reforma Agrária (INCRA).

Destacamos que na política pública dos territórios rurais a Agricultura Familiar é utilizada como conceito chave para denominar o principal público desta ação. Todavia, optamos neste trabalho pelo conceito de camponês para nos referirmos aos trabalhadores e pequenos proprietários de terras (assentados advindos da política de Reforma Agrária e proprietários tradicionais), utilizando o trabalho familiar especialmente nas atividades produtivas, recriando assim, seu modo de vida camponês baseado na tríade: terra, trabalho e família. (ALMEIDA, 2006).

\title{
A agricultura capitalista no território rural do Bolsão
}

A agricultura capitalista, comumente chamada pela mídia de agronegócio, caracteriza-se pelo latifúndio e produção de commodities. Segundo Thomaz Júnior (2010), em parte de Mato Grosso do Sul (e outros estados) localiza-se o polígono do agrohidronegócio, como parcela da atuação de empresas capitalistas, principalmente do setor sucroalcoleiro.

\begin{abstract}
Em outros termos, essa demarcação territorial contempla diferentes formas de expressão do agronegócio (soja, milho, eucalipto), nessa porção do território brasileiro e da Bacia do Paraná, a contar com o Oeste de São Paulo, Leste do Mato Grosso do Sul, Noroeste do Paraná, Triângulo Mineiro e Sul-Sudoeste de Goiás, representa a maior plantação de cana-de-açúcar [e eucalipto], também de concentração de plantas agroprocessadoras, e de produção de álcool e de açúcar do país (THOMAZ JÚNIOR, 2010, p.95).
\end{abstract}

No polígono do agrohidronegócio, mais especificamente no Território Rural do Bolsão, o campo é caracterizado pelo latifúndio, pela agropecuária extensiva e produção de soja. Na última década, a região Leste de MS sofreu grandes alterações no uso da terra com a territorialização do complexo eucalipto-celulose, composto por extensas plantações de eucalipto nos municípios de Três Lagoas, Brasilândia, Selvíria e Água Clara, processados por duas indústrias: FIBRIA e Eldorado Brasil. 
A territorialização do complexo de celulose e papel na região de Três Lagoas (e parte do Território do Bolsão) tem implicado em impactos sociais e ambientais. Com isso,

[...] a vinda de indústrias para Três Lagoas e, de modo particular, as indústrias de celulose e papel tem alterado profundamente o uso e ocupação do solo gerando uma série de impactos tanto na área rural como urbana. As terras do município que já produziram arroz, feijão, milho, café, deixaram de produzir comida para agora ter seu uso prioritário definido pelos interesses das indústrias de papel e celulose (KUDLAVICZ, 2010, p.166).

No trabalho intitulado "Alterações no Uso e Cobertura da Terra em Decorrência da Expansão do Cultivo de Eucalipto nas Microrregiões de Três Lagoas/MS e Paranaíba/MS, nos Anos de 2000, 2008 e 2014", autoria de São Miguel (2015) podemos analisar ${ }^{4}$ tanto a territorizalização deste complexo quanto o crescimento e distribuição do cultivo de Eucalipto. Condição evidenciada no mapa 2, onde observamos o crescimento da área plantada de Eucalipto que salta de 1,86\% em 2000 passando a ocupar 8,33\% em 2014.

Outra característica observada no mapa é a elevada porcentagem da área destinada a pastagens: 72,11\% da área em 2000 reduzindo para 67,47\% em 2014. Haja vista, que ao ponderar a questão agrária brasileira é necessário considerar que o uso de pastagem, também é parte da agricultura capitalista. Cabe destacar que o Território Rural do Bolsão/MS é composto por município destas duas microrregiões, como o mapa 2 apresenta.

\footnotetext{
${ }^{4}$ Em sua pesquisa, Miguel (2015) não analisou os municípios de Chapadão do Sul e Cassilândia. No entanto, trabalhos de campo e os dados do Censo Agropecuário do IBGE indicam que em Chapadão do Sul predomina o cultivo da cana de açúcar e soja, já em Cassilândia, a agropecuária é a principal atividade no campo.
} 


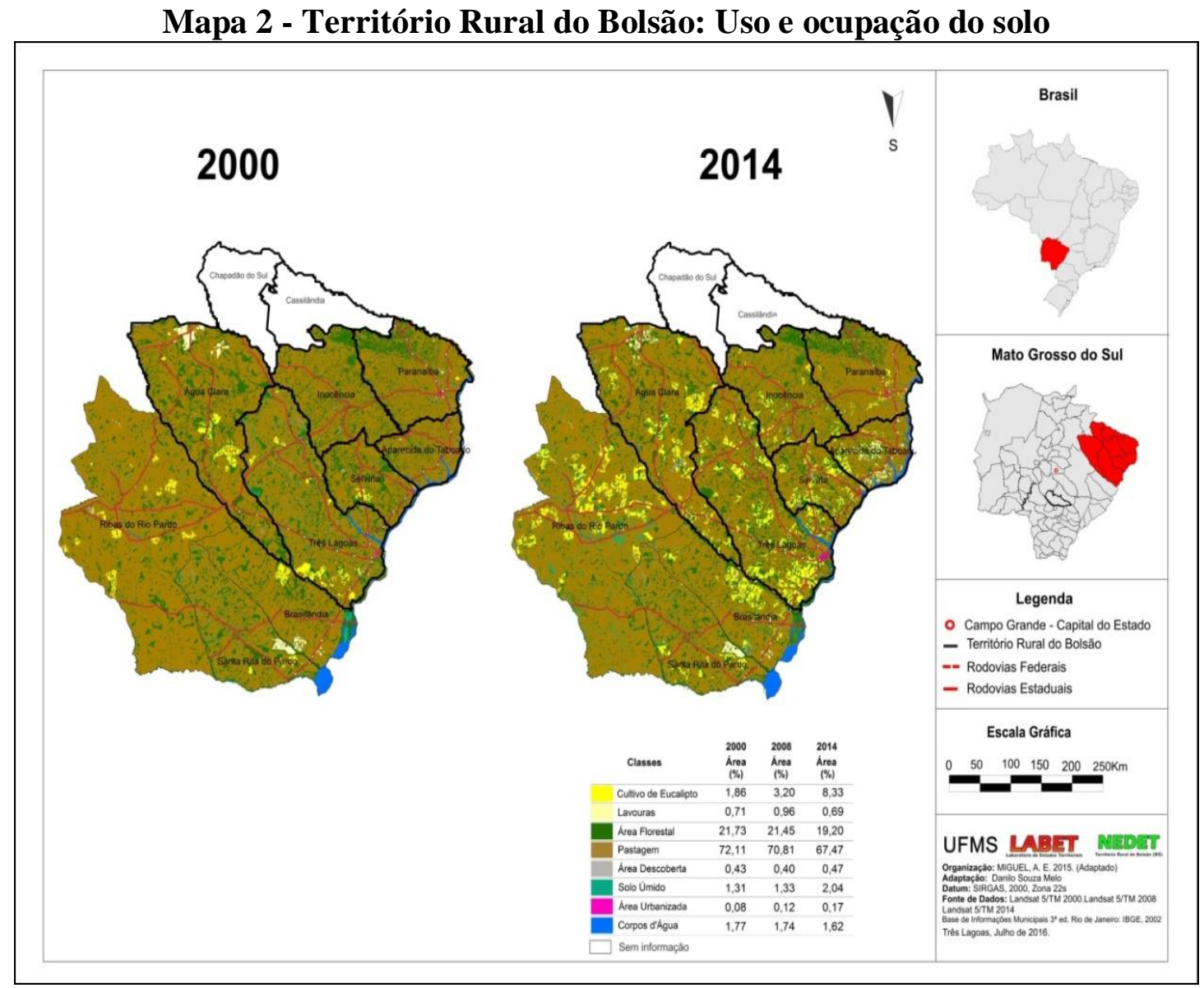

Fonte: São Miguel, 2015.

Cabe destacar que o Território do Bolsão é marcado por elevada concentração fundiária como apresenta a tabela 1 organizada a partir do Censo Agropecuário de 2006. Observa-se a predominância da média e grande propriedade, visto que os estabelecimentos com tamanho de 0 até 10 hectares são 7,6\% do total de estabelecimentos e ocupam $0,05 \%$ da área total. Os estabelecimentos com tamanho de 200 ou mais hectares são 54,21\% do total de estabelecimentos e ocupam $95,54 \%$ da área total do território.

Tabela 1 - Território Rural do Bolsão: Estrutura Fundiária (2006)

\begin{tabular}{c|c|c}
\hline \multirow{2}{*}{ Grupos de área total } & \multicolumn{2}{|c}{ Território Rural do Bolsão } \\
\cline { 2 - 3 } Mais de 0 a menos de 10 ha & Estabelecimentos \% & Área \% \\
\hline De 10 a menos de 20 ha & 7,6 & 0,05 \\
\hline De 20 a menos de 50 ha & 4,91 & 0,12 \\
\hline De 50 a menos de 100 ha & 12,52 & 0,67 \\
\hline De 100 a menos de 200 ha & 9,85 & 1,15 \\
\hline De 200 a menos de 500 ha & 10,91 & 2,47 \\
\hline De 500 a menos de 1000 ha & 19,5 & 10,31 \\
\hline De 1000 a menos de 2500 ha & 13,6 & 15,52 \\
\hline
\end{tabular}


Fonte: IBGE - Censo Agropecuário 2006. Organizado pelo autor.

Nessa perspectiva, é fundamental entendermos que historicamente, no Brasil, os grandes proprietários de terra e, atualmente, capitalistas/latifundiários, atuaram e atuam monopolizando a propriedade privada da terra por meio de instrumentos legais e ilegais, bloqueando assim o acesso à terra por parte do campesinato.

Quando analisamos o estado de Mato Grosso do Sul, especificamente o Território Rural do Bolsão/MS, é visível as novas dinâmicas no campo, intensificadas desde 2006, em que o latifúndio da pecuária vai cedendo espaço para as atividades de monocultivo, representado por grandes empresas do complexo eucalipto-celulose. Todavia, percebemos que o campesinato não pode ser considerado literalmente submisso aos processos de dominação da elite agrária no campo, pois historicamente lutou para entrar na terra, e nela permanecer e recriar o seu modo de vida camponês.

Essa contradição no campo acontece porque, diante da dominação dos fazendeiros, da expropriação territorial causada pelos latifundiários e da exploração econômica do latifúndio, com a inserção de empresas capitalistas no campo, o “[...] movimento dos sem-terras surge como uma manifestação da sociedade organizada objetivando modificar a ordem estabelecida no campo (FABRINI, 2001, p. 65)”. E, nesse movimento, ele - o camponês - não fica calado; ao contrário, resiste e recria formas para entrar na terra novamente, ou possuí-la pela primeira vez.

\section{A agricultura camponesa no território rural do Bolsão}

Ao discutirmos a respeito da agricultura camponesa no Território Rural do bolsão é preciso considerar que contraditoriamente, o camponês, ante a provável ameaça de perder sua parcela de terra, rebela-se contra as ações dominantes, resistindo e superando a expulsão, conquistando o seu direito a terra e recriando múltiplos caminhos para permanência nela.

Alguns dos caminhos trilhados pelos camponeses para retornarem à terra é a luta pela política pública de Reforma Agrária, que por meio da distribuição da terra, tende a modificar a estrutura fundiária, mesmo que pontualmente. Para Oliveira (2006) a implantação de programas de reforma agrária via financiamento de compra e venda de terras, como é o caso da reforma agrária de mercado, adotado no Brasil, são expressão da política de 
contrarreforma, uma vez que a "[...] aquisição da terra rural deu-se sob a lógica do mercado, ou seja, a terra foi negociada como uma mercadoria capaz de gerar renda capitalizada para os proprietários rentistas [...]" (OLIVEIRA, 2006, p. 3).

Apesar de existir no Território Rural do Bolsão agricultores camponeses que tiveram acesso a terra de maneira diferente da tradicional reforma agrária, que, diga-se de passagem, compõem considerável diversidade do campesinato no território estudado, nossa análise se atentará aos camponeses nos projetos de Reforma Agrária.

Desta forma, a atual luta pela reforma agrária brasileira aponta-nos a existência de um problema agrário estrutural. Isso significa dizer que a terra nesse país, continua sendo equivalente de capital nas mãos dos capitalistas, e o seu domínio territorial histórico é responsável pela pobreza e violência na sociedade rural brasileira.

No Território Rural do Bolsão temos exemplos da insistente luta de recriação travada pelos camponeses. Segundo os dados da Secretaria de Desenvolvimento Territorial (SDT) a luta camponesa no Território Rural do Bolsão é representada por 8 projetos de assentamentos de reforma agrária com 730 famílias como indica a tabela 2.

Tabela 2 - Território Rural do Bolsão: Dados da Reforma Agrária (2015)

\begin{tabular}{c|c|c}
\hline Município & $\mathbf{N}^{\mathbf{0}}$ de famílias assentadas & $\mathbf{N}^{\mathbf{0}}$ de projetos de reforma agrária \\
\hline Água Clara & 0 & 0 \\
\hline Ap. Taboado & 0 & 0 \\
\hline Cassilândia & 0 & 0 \\
\hline Chapadão do Sul & 59 & 1 \\
\hline Inocência & 0 & 0 \\
\hline Paranaíba & 110 & 3 \\
\hline Selvíria & 441 & 3 \\
\hline Três Lagoas & 120 & $\mathbf{8}$ \\
\hline Total & $\mathbf{7 3 0}$ & $0 r$ peto
\end{tabular}

Fonte: SDT/Ministério de Desenvolvimento Agrário 2015. Organizado pelo autor.

Como observado na tabela acima, não há um grande número de projetos de assentamentos rurais no Território Rural do bolsão, dado sua área. Assim, os oito projetos de assentamento e suas 730 famílias do Território Rural do Bolsão estão localizados em apenas quatro municípios do Território: Chapadão do Sul, Paranaíba, Selvíria e Três Lagoas (mapa $3)$. 


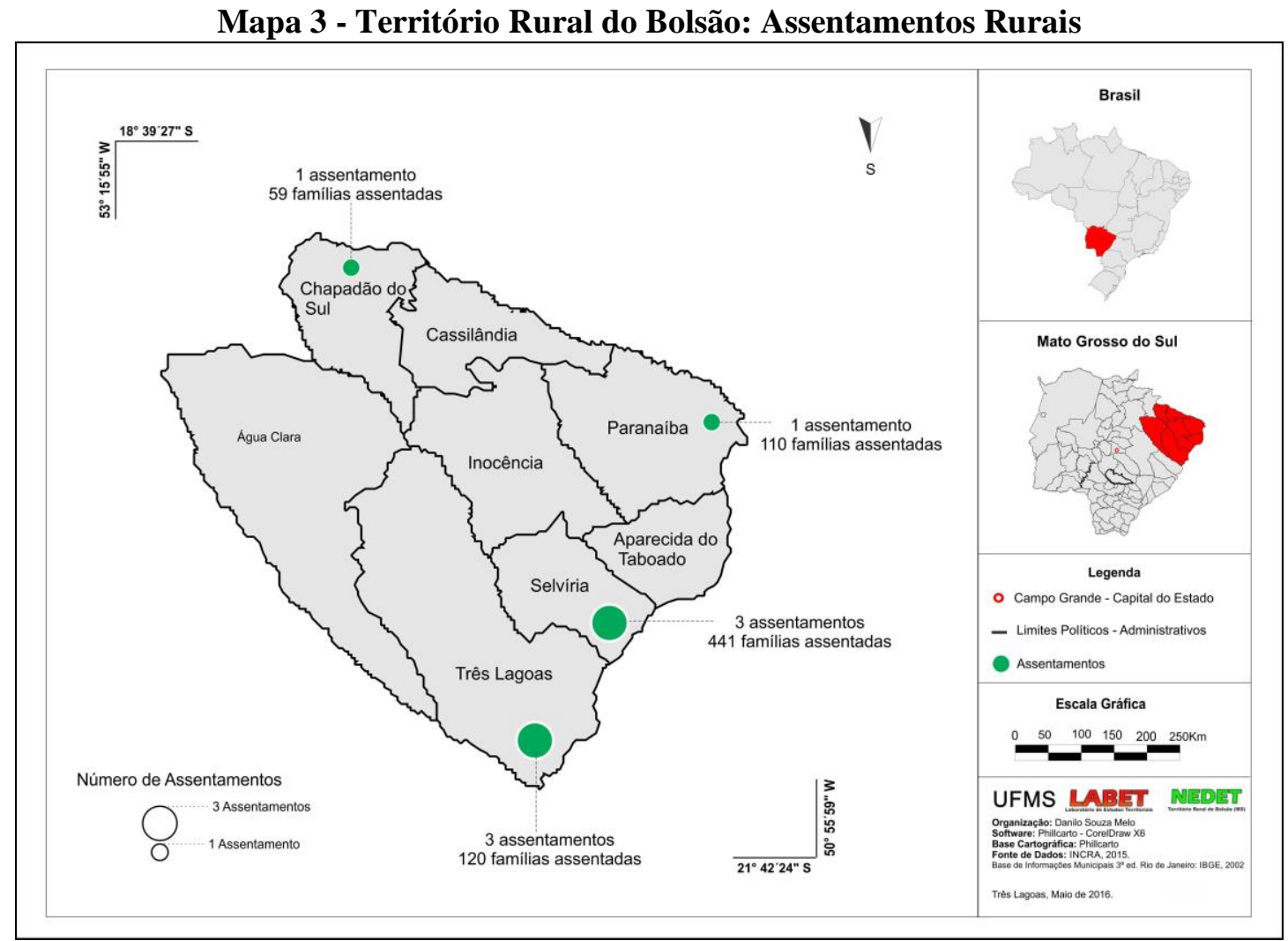

Fonte: INCRA, 2015.

Conforme observado em saídas de campo, a maioria das famílias assentadas, ainda vive em condições muito precárias de moradia e sem assistência técnica eficaz. Esta dura realidade ainda é agravada pela baixa fertilidade do solo, épocas prolongadas de seca, pela quase ausência de apoio técnico e dificuldades na comercialização da produção. Aliado a estas dificuldades, observamos também que há, sem dúvidas, um visível estado de abandono dos projetos de assentamentos implantados por parte do Estado, fato que tem contribuído para o aumento das dificuldades enfrentadas pelo campesinato para permanecerem na terra.

O envelhecimento da população rural no Território do Bolsão é outro processo atenuante. Quadro presente na maioria dos projetos de assentamento decorrente tanto pela demora na conquista da terra quanto o deslocamento dos jovens para as cidades. Destacamos que uma das preocupações presentes em alguns relatos é o deslocamento dos jovens para a cidade, provocado pela falta de incentivos no campo para a juventude camponesa, considerado outro ponto responsável pela migração dos camponeses para a cidade.

A maioria dos jovens deixa o campo e vão para a cidade em busca de melhores condições de emprego e educação. Os já citados problemas de infraestrutura e assistência 
técnica também afetam os jovens nos assentamentos rurais. Como podemos observar no relato 5 abaixo:

É com tamanha tristeza que observamos esse embate aqui no Distrito de Arapuá, a falta de incentivo por parte do governo para com as pequenas propriedades e aos assentamentos ao entorno do distrito, agravado ainda mais pela inserção do monocultivo do eucalipto na região, estão deixando muitas famílias sem perspectiva de renda ou um futuro melhor. Dessa forma presenciamos sempre a migração dos jovens, que buscam na cidade uma qualificação profissional para trabalhar nas indústrias ou um trabalho que lhes de uma renda complementar para ajudar nos estudos ou a própria família.

Muitos desses jovens cresceram aprendendo junto ao pai a lidar com o trabalho do campo, essa forma de trabalho vem sendo escasso nas fazendas e nas pequenas propriedades, onde muitas vezes não conseguem retirar uma renda que lhes forneça o bem necessário a vida familiar, impossibilitando dessa forma o jovem de ter uma renda, como eles falam um dinheirinho no final do mês.

Esse processo de migração do jovem esta sendo sentido em todos os segmentos dentro do distrito, como ex. podemos mencionar a escola, que diminuiu consideravelmente o numero de matriculas no ensino médio e no laser, notamos a falta dos jovens nos torneios que eram famosos pelo numero de times que revezavam o dia todo dento do campo.

Para nos moradores do distrito, seria de grande importância à implantação de cursos voltados aos jovens camponeses, motivando eles a permanecer no campo e consequentemente fortalecer a identidade camponesa.

Diante dessas dificuldades, parte da juventude que ainda residem no sítio, assim como seus pais, acabam trabalhando nas papeleiras (operando tratores e executando trabalhos manuais). Esse tipo de trabalho pode ser entendido como estratégia de resistência camponesa, uma vez que, permite a permanência dos jovens no sítio. Como o caso do Assentado do projeto de Assentamento São Joaquim, que ao ser indagado dos motivos que contribuíram para entrar na empresa, ele afirma que quando chegou ao assentamento com sua família:

[...] não tinha serviço, eu não tinha nada, tinha que arrumar um serviço! Primeiro serviço que apareceu: Eldorado, fui trabalhar lá. [...] Aqui na época não tinha condições de viver aqui dentro, ou você trabalhava pra fora, ou você saia do assentamento. Aqui não tinha opção pra nada, quando cheguei aqui. Aqui era um lugar pra se morar [...] $]^{6}$ (SILVA, 2014, p.144).

\footnotetext{
${ }^{5}$ Entrevista realizada em 10/09/2016 na Universidade Federal de Mato Grosso do Sul - Campus de Três Lagoas, com moradora do Distrito de Arapuá e Aluna do programa de Especialização em Educação do Campo.

${ }^{6}$ Assentado do projeto São Joaquim, 2014 - Selvíria/MS. Transcrição de parte do relato do assentado, ex empregado das empresas de eucalipto referente aos motivos que favoreceram a busca de renda fora do lote Selvíria/MS. Entrevista, Trabalho de campo realizada em Maio de 2014 no projeto de assentamento São Joaquim.
} 
Para Almeida e Paulino (2010, p. 21), a atividade assalariada fora da propriedade familiar é uma forma de resistência camponesa nos momentos de crise econômica, pois "[...] é precisamente o fato de não visar o lucro de sua atividade econômica, mas a reprodução do grupo familiar [...] que permite respostas adaptativas às crises, recorrendo até mesmo ao trabalho acessório não agrícola e à migração [...]”.

A educação é outra dimensão que afeta a juventude camponesa no Território Rural do Bolsão. Pois, no Território há poucas escolas no campo, a saber: Selvíria (1), Paranaíba (1), Inocência (2), Três Lagoas (1). Destas, poucas oferecem o ensino médio, forçando o deslocamento dos jovens para as cidades para concluírem o ensino básico, juntamente com outros problemas de infraestrutura, currículo e quadro de funcionários.

Segundo Kudlavicz e Almeida (2014), ao analisarem o contexto do Programa de Reforma Agrária na região, especialmente no município de Três Lagoas (MS), advertem que essas condições de abandono dos assentamentos têm contribuído para a "privatização da reforma agrária", resultante do conjunto de programas sociais desenvolvidos pelas empresas do agronegócio, ligadas ao complexo eucalipto-celulose, nos projetos de assentamento.

Programas desenvolvidos especialmente para a obtenção de certificações para a venda da produção (celulose) nos mercados estrangeiros. Estes programas são vistos pelos assentados como garantidores de sua permanência no campo, conforme revela o trecho da entrevista concedida a Kudlavicz; Almeida (2014, p. 3).

\footnotetext{
Práticas empresariais que devem ser entendidas num contexto específico, qual seja o de que as empresas receberam volumosos incentivos fiscais (e ambientais) para se estabelecerem na região e que devem conduzi-los em forma de "desenvolvimento sustentável" - leia-se restituir parte destes benefícios em favor da comunidade local na forma de projetos sociais. A isso se mescla a necessidade de adquirirem o selo de origem que funciona como sinal aos consumidores globalizados que o produto, ou seu componente, é proveniente de uma floresta que não impactou seu entorno, em outras palavras: ambientalmente adequado, economicamente viável e socialmente justo.
}

Esta dualidade é tida como salutar para diversos autores, entre eles Ricardo Abramovay (1992; 2007) e José Graziano da Silva (1999). Eles entendem ser possível relação harmônica entre a grande propriedade monocultora e a pequena unidade de produção, instalada sob a ótica da reforma agrária. No entanto, para Oliveira (2004), Shanin (2008), Paulino (2010), Almeida (2010, 2012), a realidade apresentada demonstra ser inconciliável as duas lógicas de produzir no campo, basicamente porque a monocultura se nutre de modelo industrial altamente impactante do ponto de vista ambiental e social. 
Algumas percepções acerca das contradições dessa dualidade já foram identificadas em entrevistas com alguns assentados que participam dos programas desenvolvidos pelas empresas nos assentamentos. Isto porque, ao mesmo tempo em que as famílias aceitam a ajuda da empresa, elas estão preocupadas com o cerco dos projetos de assentamento ocasionado pelo plantio de eucalipto, diminuição da água nos córregos e o duro ataque dos animais nas lavouras e hortas em busca de alimentos, intensificados após a vinda das empresas para a região. Como podemos observar na fala do assentado do Projeto 20 de Março que ao ser questionado a respeito dos problemas ao redor do assentamento ele diz que:

[...] hoje a realidade local nossa é assim, acho que isso já passou de ser local só, pra mim chega ser uma realidade estadual. $\mathrm{O}$ eucalipto hoje aí se tornou um mar verde néh. Então quer dizer, o que acontece dentro desse sistema, primeiro que hoje temos um ataque severo dos animais, coisa que há alguns tempos atrás nós não tínhamos, porque quando falo o ataque severo dos animais é tucano acabando com lavoura de mamão, lobinho comendo lavouras de melancia, seriema acabando com lavoura de abóbora. Você entendeu, então quer dizer não é culpa dos animais, infelizmente não é, até porque eles têm que comer também. Para nós é ruim porque estamos perdendo produto de vender, mas entendemos também que eles precisam comer também, que não tem, não tem. Vão comer o quê? Olha em volta de nós, tem só eucalipto. Eles não são coala, não comem eucalipto. [...] Onça, onça aqui embaixo tem uma reserva ali, uma reserva maior né, tem relatos que, na verdade não se sabe do quê, que abateram alguns animais, mas não sabe direito o que é, não sabe se é jaguatirica ou se é onça pintada [...] (Assentado do projeto 20 de Março, 2016 - Três Lagoas/MS).

A respeito das alterações no nível da água nos córregos encontramos relatos da população rural residente nos arredores dos plantios de eucalipto, tanto próximo às áreas de influência da Fibria, quanto da empresa Eldorado Brasil. Dentre eles destacamos o relato do assentado do projeto Alecrim, que observa a diminuição de água num córrego próximo do assentamento:

Então essa represa aqui era cheia, era cheia, e aqui onde nóis estamos aqui que hoje levante esse pó, aqui era o ladrão, a água descia aqui oh! E saia ali pra baixo. Por sinal você tá vendo lá o quanto que ela abaixou, a lá oh! e é porque nessa última chuva que deu ela já pegou água. Ela tinha menos água. A nascente era aqui em cima oh! Só que já secou, já secou. Aqui é só água da chuva. ${ }^{7}$ (SILVA, 2014, p.144).

Ao ser questionando se a diminuição da água na represa não se devia à falta de chuva, pois ainda estávamos no início da estação chuvosa, o entrevistado assim respondeu:

\footnotetext{
${ }^{7}$ Assentado do projeto Alecrim, 2013 - Selvíria/MS . Transcrição de parte do relato de um assentado que conhece a região há mais de 10 anos. Entrevista, trabalho de campo realizada em Janeiro de 2014, no projeto de assentamento Alecrim, localizado no Município de Selvíria/MS.
} 
Isso daqui eu conheço ha sete oito anos que eu conheço, e sempre tinha água, muita água, a água sempre correndo por aqui [...] E conheço outras áreas também, que essa já não é, não faz parte nossa, que o açude secou e era açude muito grande e já secou. Por sinal o córrego do Queixada onde é que eu vivia na beira da estrada lá que eu tomava banho no poço lá, mergulhava, hoje a água não vem na minha canela, então isso já esta causando uma preocupação. São vários pontos, já notamos que houve muita diminuição de água, e muita diminuição [...] onde o pau está branco era onde era a água onde é que está preto para cima não a lá oh! O sinal esta lá. Eu cansei de chegar aqui onde tá aquela cerquinha ali oh e entrar dentro da água até ali, e meter o braço e chegar lá, eu sentar em cima daquela cabeça de capim lá oh! Cansei. E hoje ta essa situação ai oh! que dá dó [quando ela começou a reduzir?] Ela foi reduzindo aos poucos. Ela começou perder força mesmo foi depois que o eucaliptos cresceu aqui, que ela perdeu força. Porque aqui na costa da nascente ali oh, então tem eucalipto, só tem um carreador que passa e a gente. Eu conheci essa área antes de eucalipto, esse eucalipto deve ter mais ou menos agora uns seis anos, já cortou [tem outras áreas nessa situação?] aqui era um corgo, e esse corgo ai pra baixo secou também $[\ldots]$

\section{Figura 1 - Córrego do Queixada com baixo nível de água}

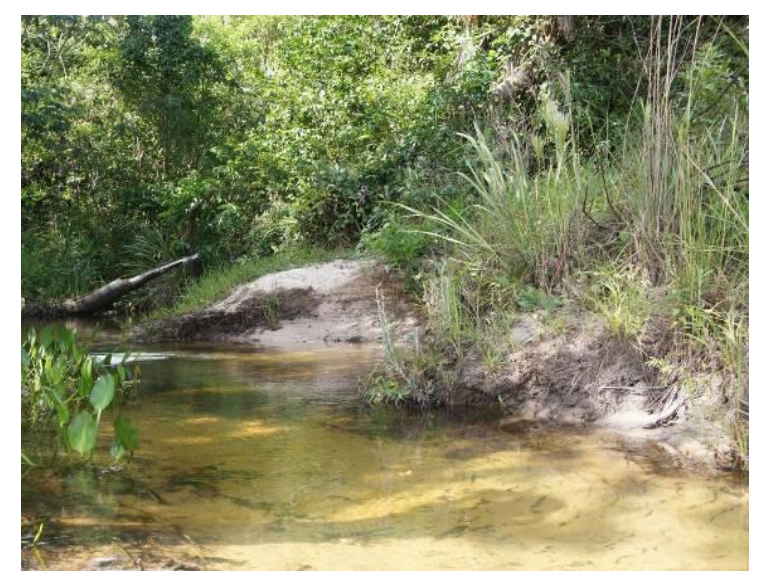

\section{Figura 2 - Represa dentro da APP do assentamento Alecrim com baixo nível de água}

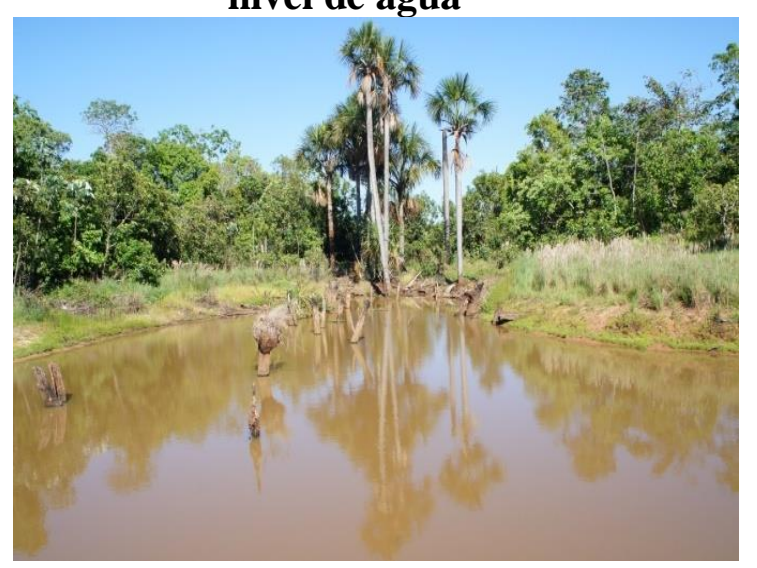

Fonte: autores, 2014/2015.

Desta forma, notamos que ante a realidade de abandono por parte do Estado, ao lado da implantação de programas sociais desenvolvidos pelas empresas de celulose e papel tem delimitado a resistência camponesa em bases de subalternidade. Pois consideramos que essa parceria das empresas aos projetos onde a ação do Estado é ausente são ferramentas usadas para desviar a atenção da sociedade acerca da incompatibilidade de convivência destas lógicas distintas sobrepostas no território. Nesse sentido Silva (2014, p. 197) considera que,

O visível estado de abandono e o processo de privatização dos projetos de assentamentos fazem parte do plano de paralisação da política pública de reforma agrária [...]. A Situação impõe aos assentados de Três Lagoas e Selvíria resistência determinada pela conformidade, melhor, pela subalternidade. 


\section{A questão agrária no território rural do Bolsão/MS: Algumas aproximações}

Outro processo visível, é que dada a precariedade dos assentamentos do Território do Bolsão, os camponeses acabam sendo obrigados a deixarem o campo em busca de outras fontes de renda. A saída do sítio $^{8}$ pode ser permanente ou momentânea. Na primeira, as famílias em razão das dificuldades em permanecer na terra, deixam o campo em direção as cidades. Já na saída momentânea, o assentado se ausenta em alguns períodos para trabalhar fora do sitio. No caso aqui estudado, há um elevado grau de assalariamento dos assentados nas empresas de celulose e papel como evidencia a fala ${ }^{9}$ do assentado no Projeto São Joaquim (Selvíria/MS).

[...] a maioria do pessoal aqui até então, vive assim trabalhando na firma [...] do eucalipto. É uma firma do eucalipto, em parceria com a Eldorado, é uma terceirizada. Tem três ônibus que circula aqui dentro que leva o pessoal cedo, e traz praticamente quase às 10 horas da noite [22h] pra cá (...). (Grifo Nosso). (SILVA, 2014, p.144).

Lembramos que dois elementos de análise são essenciais para a compreensão desta realidade camponesa, até certo ponto ambivalente. O primeiro é que o camponês não rompe com as atividades de produção no sítio; elas apenas são realizadas por outros membros da família, ou por ele mesmo nos intervalos de folga do trabalho, em especial nos finais de semana. Essa relação é típica nos assentamentos estudados que estão no raio de atuação das papeleiras. Muitos, daqueles que, durante a semana, estavam na lida nos plantios de eucalipto, nos finais de semana dedicavam-se a atividades de produção no lote, entre as quais o trabalho com a horta, o mutirão para conserto de cercas ou ampliação das casas.

Como enfatiza Shanin (2008, p. 27):

A economia Familiar tem seus próprios modelos, suas próprias estruturas e seu próprio significado primordial que não desaparece. Por isso, sob certas condições, a economia camponesa é mais eficiente do que economias não camponesas. Os membros da família e o modelo familiar básico de bem-estar econômico estão envolvidos de forma particular num sistema de uso do trabalho que não é trabalho assalariado, mas trabalho familiar. Daí a sua capacidade para resolver problemas que outros tipos de economia não resolveriam de uma maneira tão eficaz e pouco dispendiosa.

\footnotetext{
${ }^{8}$ O termo sítio é entendido como terra de trabalho, morada de vida, [...] lugar da horta, do pomar, do cachorro, do gato, da galinha, do porco, do paiol, enfim, é o prolongamento do trabalho cotidiano. Assim, por mais que se professe um espaço da distinção (casa, quintal, pasto, e lavoura), a lógica de sua representação obedece a um habitus da unidade produtiva camponesa, em que família, trabalho e terra não se encontram divorciados. Situação que, por sua vez, confere as marcas da territorialização camponesa no território[...]( ALMEIDA, 2006, p. 271)

9 Assentado do Projeto São Joaquim, 2012 - Selvíria/MS. Entrevista concedida a Mariele de Oliveira Silva em trabalho de campo realizado em Setembro de 2012 no projeto de assentamento São Joaquim (Selvíria/MS).
} 
Situação nítida do decorrer de nossa pesquisa. Em alguns deles percebemos a transitoriedade dessa situação, isso porque alguns assentados ao conseguir equilibrar a situação financeira da família ou ao chegar a época das chuvas, romperam o seu vínculo empregatício e volta a dedicar-se, em tempo integral, às atividades do sítio:

\begin{abstract}
O sonho era plantar e conseguir tirar o sustento daqui de dentro da terra, de dentro da terra, trabalhava que néh doido ai, e vai, vai, vai, daqui um pouco estava passando até necessidade, ai fui trabalhar numa empresa, na época era Florestal Brasil, ela mudou a fantasia agora é Eldorado, saia daqui cinco hora da manha, chegava aqui oito nove hora da noite, ai se já viu, o que eu tava fazendo aqui no sitio, só vinha dormir [...] entojei, entojei mesmo, teve um ano que trabalhando nessa empresa eu perdi quatro vacas atolada, ai fui fazer umas contas na época valia mil e quinheto cada vaca, que até hoje não subiu quase nada, perdi seis cruzeiro [reais] ai fui fazer a conta, eu perdi seis meses de emprego, vou ter que trabalhar seis meses agora pra mim recuperar o prejuízo que eu tomei, porque se eu tivesse lá essas vacas não tinham morrido, entendeu? Ai eu sai [...] eu vou achar um jeito de ganhar dinheiro nesse negocio aqui [lote], eu vou achar um jeito, com o lote, tem que viver, tem que viver com isso daqui! Se a foia [hortaliças] não deu, mas o milho tem que dar, se o milho não deu a abobora tem que dar [...] porque você não pode mexer com uma cultura só, você tem que mexer com várias culturas, porque se naquele ano a hora que você ter que vender ta ruim, tem aquela outra que esta te acudindo $[\ldots]^{10}$ (SILVA, 2014, p.144).
\end{abstract}

Apesar de o trabalho assalariado ser estratégia de resistência camponesa, para manter a família no campo, como indicou os estudos de Silva (2014) e Fonseca (2014), essa situação é vista como limite do camponês na reforma agrária, que pode resultar na saída permanente do campo.

Mas não apenas de recriação tutelada pelas empresas vivem os assentados. Em alguns municípios do Território Rural do Bolsão/MS notamos a resistência inovada a partir da apropriação de políticas públicas, como os mercados institucionais: PAA - Programa de Aquisição Alimentar e o PNAE - Programa Nacional da Alimentação Escolar. Estes mercados institucionais têm no seu conjunto de objetivos o fortalecimento de canais de comercialização locais e regionais, bem como a ações que estimulem, promovam, e valorizem a biodiversidade e a produção orgânica e agroecológica de alimentos.

Houve também o fortalecimento dos grupos informais de consumo: feira local, comercialização a domicilio, ao lado de dois projetos de extensão desenvolvidos pela Universidade Federal de Mato Grosso do Sul, campus de Três Lagoas: sacolas agroecológicas

\footnotetext{
${ }^{10}$ Assentado do projeto Alecrim, 2014 - Selvíria/MS. Transcrição de parte do relato do assentado, referente ao rompimento com vinculo empregatício com as empresas de eucalipto - Selvíria/MS. Entrevista, Trabalho de campo realizada em Janeiro de 2014 no projeto de assentamento Alecrim.
} 
e a Feira de produtos em Transição Agroecológica da Agricultura Camponesa em Três Lagoas - MS (PREAE/2016) - ambos coordenado pela Profa. Dra. Rosemeire A. de Almeida.

Tanto os mercados institucionais como os grupos informais são exemplos dos chamados canais curtos de comercialização, tem ajudado os assentados a superarem os empecilhos colocados pela lógica do sistema capitalista de domínio do mercado, facilitando a comercialização dos produtos da agricultura familiar camponesa diretamente ao consumidor, ou seja, não só de conformidade se faz essa resistência, mas também da utopia da emancipação.

Figura 3 - Canais Curtos de Comercialização: Feira, mercados institucionais e Projetos de Extensão Universitário.

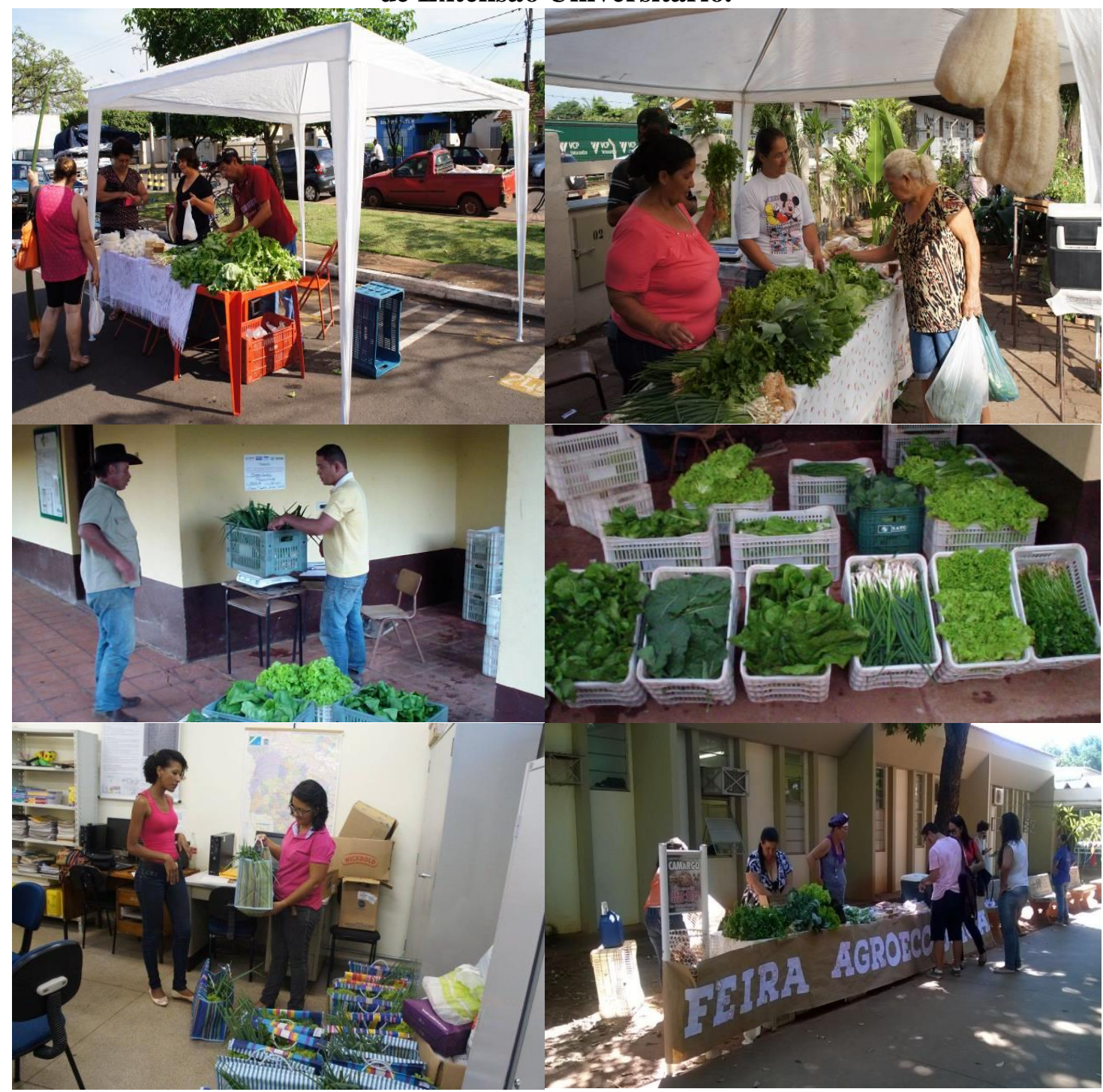

Fonte: autores, 2014/2015. 
Como já apresentado anteriormente, o envelhecimento da população rural no Território do Bolsão é outro processo visível. Neste sentido, o NEDET do Bolsão e a UFMS atuam com o objetivo de incentivar a permanência da juventude no campo, como exemplo, a organização do Polo do Curso de Especialização em Educação do Campo (2014-2016) na Universidade Federal de Mato Grosso do Sul/ Campus de Três Lagoas. Esse Curso de Especialização com Polo em Três Lagoas e Paranaíba tem como objetivo a formação de professores da rede básica de ensino que atuam em escolas localizadas especialmente no campo.

Além da Especialização, há o projeto de Extensão intitulado "Formação continuada de Educação no/do Campo para professores e gestores da Escola Municipal Rural São Joaquim - Selvíria (MS)". Coordenado pela Profa. Dra. Rosemeire Aparecida de Almeida, esse projeto objetiva envolver a comunidade escolar do Assentamento São Joaquim no projeto de Educação no/do Campo no sentido de contribuir para que formem e capacitem crianças e jovens com conhecimentos teórico-metodológicos e compromissos voltados às especificidades do campo e para o estabelecimento de formas sustentáveis de produção, a partir do principio de justiça social e ambiental para a conquista de melhorias na qualidade de vida e permanência das pessoas no campo.

Com o intuito de contribuir na organização de propostas que auxiliem na permanência da juventude no campo algumas atividades estão sendo organizadas pelo Núcleo de Extensão em Desenvolvimento Territorial (NEDET) do Bolsão (MS). Como exemplo, temos o Encontro da Juventude Camponesa, que ocorrerá em agosto de 2016, este encontro objetiva reunir jovens camponeses de todo o Território Rural do Bolsão e fomentar discussões e levantar demandas a respeito do cotidiano da juventude no campo.

O encontro permitirá ainda a formação do Comitê de Jovens, que consiste em um espaço dentro da política pública de Desenvolvimento Territorial Rural para acesso a financiamentos, programas e projetos do governo federal. O Comitê de Jovens possibilita contato direto com o poder público municipal e estadual. 


\section{CONSIDERAÇÕES FINAIS: A QUESTÃO AGRÁRIA NO BOLSÃO}

Consideramos que as especificidades observadas no Território Rural do Bolsão/MS, em que: as empresas fundamentadas na expansão da propriedade capitalista, por meio do complexo eucalipto-celulose, soja, cana de açúcar, etc., que historicamente têm travado a implantação de projetos de reforma agrária em dadas regiões brasileiras, com a elaboração de programas sociais são vistas como parceiras dessa política. E contraditoriamente há visível estado de abandono dos assentamentos por parte do Estado, até mesmo na falta da instalação de infraestruturas básicas. Condições que vêm suscitando novas abordagens a respeito da questão agrária no campo atualmente.

Deste modo, a questão agrária Brasileira e no Território Rural do Bolsão é motivada e compreendida pelo desenvolvimento do capital no campo brasileiro, e que, segundo Oliveira (1991; 2004; 2010), ocorre de maneira desigual, combinada e contraditória, ou seja, o capital ao reproduzir suas relações capitalistas, promove, ao mesmo tempo, relações não tipicamente capitalistas. O campesinato, assim, é parte das contradições do desenvolvimento do capitalismo no campo. No entanto, o campesinato é mais que uma contradição, é uma classe social que luta diariamente para conquistar e se manter na terra.

Almeida (2006) ressalta o (re)inventar das formas de resistência para manutenção da tríade: família, terra e trabalho. Assim, para os camponeses;

[...] sua reprodução e sua luta diária são feitas tendo como base a manutenção de valores considerados tradicionais: família, terra e trabalho. Esse parece ser o limite, mas também o seu possível, uma vez que tem sido capaz, nessa luta, de (re)inventar novas formas de enfrentamento, um novo jeito de lutar, o que tem garantido sua reprodução para muito além das determinações do capital (ALMEIDA, 2006, p. 108)

O campesinato, para muitos estudiosos marxistas, como Kautsky e Lênin, estaria fadado ao desaparecimento diante do desenvolvimento do capitalismo (PAULINO, ALMEIDA, 2010). Apesar das análises negativas, o campesinato continua existindo, resultado do próprio capitalismo. Desta maneira, “[...] o camponês desempenha um contraditório papel que, de um lado, expressa a sua resistência em desaparecer e, de outro lado, é resultado do próprio capitalismo que não o extingue”. (MOURA, 1986, p. 19). 
Dessa forma, a questão para o camponês era: ou ele se metamorfoseia em agricultor familiar e se integra ou se mantém como ele mesmo e se desintegra. Nestes referenciais não há futuro, porque não há perspectiva desse sujeito continuar sendo camponês. (FERNANDES, 2001, p.4).

[...] que o produtor familiar que utiliza os recursos técnicos e está altamente integrado ao mercado não é um camponês, mas sim um agricultor familiar. Desse modo, pode-se afirmar que a agricultura camponesa é familiar, mas nem toda a agricultura familiar é camponesa, ou que todo camponês é agricultor familiar, mas nem todo agricultor familiar é camponês. Criou-se assim um termo supérfluo, mas de reconhecida força teórico - política. E como eufemismo de agricultura capitalista, foi criada a expressão agricultura patronal (FERNANDES, 2001, p. 29-30)

Nesse sentido, o debate acerca do campesinato e sua recriação no contexto do desenvolvimento do capital no campo é fundamental para compreendermos a realidade:

Enquanto o campo brasileiro tiver a marca da extrema desigualdade social e a figura do latifúndio se mantiver no centro do poder político e econômico - esteja ele associado ou não ao capital industrial e financeiro -, o campesinato permanece como conceito-chave para decifrar os processos sociais e políticos que ocorrem neste espaço e suas contradições (MARQUES, 2008, p.58)

Assim, observamos no Território Rural do Bolsão a presença do campesinato com suas mais diversas origens (acesso a terra) e com grande número de jovens que sofrem com problemas relacionados a educação e geração de renda. É possível observar também, a (re) criação do campesinato via assentamentos de reforma agrária, crédito fundiário e compra de pequenas propriedades.

A (re)criação do campesinato ocorre no contexto de controle do território pelo capital via monopolização e territorialização.Segundo Oliveira (2003, p.106), o capital se apropria da renda da terra em dois processos: territorialização e monopolização. Na territorialização, o capital controla o meio de produção (terra), cobrando da sociedade tributo (renda) por utilizá-la. Esse processo pode ser observado no Território Rural do Bolsão com a presença da agricultura capitalista que concentra a estrutura fundiária e atualmente com a expansão do monocultivo de eucalipto.

No processo de monopolização, o capital se apropria da produção camponesa na circulação, sujeitando a renda da terra produzida pelos camponeses à lógica capitalista (OLIVEIRA, 2010, p.10). No Território Rural do Bolsão/MS a comercialização da produção camponesa possui um grande obstáculo para sua (re)criação, pois predominam monopólios de compra (redes de supermercados, Laticínios entre outros) que se apropriam da renda 
camponesa. Nesse sentido, as ações do Nedet trabalham com o objetivo de melhorar a circulação da produção camponesa como nas sacolas agroecológicas e na Feira de produtos em Transição Agroecológica da Agricultura Camponesa em Três Lagoas.

Este trabalho teve como objetivo fazer aproximações do atual contexto do campo no Território Rural do Bolsão/MS com a questão agrária. Essas aproximações possibilitam a ampliação de pesquisas neste território que norteiam a (re)criação e resistência camponesa, desenvolvimento do capital no campo, políticas públicas de aquisição de alimentos, a política pública de desenvolvimento territorial e educação do/no campo. Assim, concluímos que o Território Rural do Bolsão/MS é um importante local de estudo sobre a questão agrária, onde se apresentam características gerais do desenvolvimento desigual contraditório e combinado do capitalismo no campo e ao mesmo tempo especificidades locais.

\section{AGRADECIMENTOS}

Ao Conselho Nacional de Desenvolvimento Científico e Tecnológico (CNPq) pelo financiamento desta pesquisa.

\section{REFERÊNCIAS}

ABRAMOVAY, Ricardo. Paradigmas do capitalismo agrário em questão. São Paulo: Hucitec; Campinas: Unicamp, 1992.

. Agricultura familiar e capitalismo no campo. In:STÉDILE, João(Coord.). A questão agrária hoje. 2. ed. Porto Alegre: UFRGS, 2002. p. 94-104. ABRAMOVAY, Ricardo. Agricultura e desenvolvimento rural. Revista O Valor, p. 1-4, 14 jun. 2007.

ALMEIDA, Rosemeire Aparecida de. (Re) criação do campesinato, identidade e distinção: a luta pela terra e o habitus de classe. São Paulo: UNESP, 2006.

BRASIL. Ministério Do Desenvolvimento Agrário - MDA. Marco Referencial para Apoio ao Desenvolvimento de Territórios Rurais. Brasília: SDT-MDA. 2005.

.Um novo Brasil rural. Brasília: MDA, 2010.

. Manual do PROINF__Brasília: MDA, 2015. 
CAMACHO, Rodrigo. S. Paradigmas em disputa na Educação do Campo. 2014. Tese (Doutorado em Geografia) - Programa de Pós-graduação em Geografia da Faculdade de Ciências e Tecnologia da Universidade Estadual Paulista, campus de Presidente Prudente.

COCA, Estevan, L. Um estudo da diversidade e atualidade da reforma agrária: análise dos tipos de assentamentos do Território Cantuquiriguaçu - estado do Paraná. 2011. Dissertação (Mestrado em Geografia) - Presidente Prudente. $231 \mathrm{f}$.

CORRÊA, Vanessa, P. Desenvolvimento territorial e a implantação de políticas públicas brasileiras vinculadas a esta perspectiva. IPEA. Boletim regional, urbano e ambiental. 2009. P.23-37.

DATALUTA. Relatório Nacional 2011. Disponível em: http://www2.fct.unesp.br/nera/projetos.php. Acesso em: 03/05/2014.

FABRINI, João. A escala da luta e resistência camponesa. Revista GEOSUL. Florianópolis, v. 21, n. 42, p.63-91, jul/dez. 2006.

FERNANDES, Bernardo Mançano. Questão Agrária, Pesquisa e MST. São Paulo, Cortez Editora, 2001.

.Questão agrária: conflitualidade e desenvolvimento territorial. In: BUAINAIN, Antonio M. (Ed.). Luta pela terra, reforma agrária e gestão de conflitos no Brasil. Campinas: Editora da Unicamp, 2005.

. Entrando nos territórios do Território. In: PAULINO, Eliane T.; FABRINI, João E. (Org.). Campesinato e territórios em disputa. São Paulo: Expressão Popular, 2008.

FONSECA, Silas. R. Monocultivo de Eucalipto, Relações de Trabalho e os Caminhos da Resistência Camponesa no Assentamento São Joaquim (MS). 2014. Dissertação de Mestrado. Programa de Pós-graduação em Geografia da Universidade Federal da Grande Dourados. Dourados.

GÓMEZ, Jorge. R. M. Desenvolvimento em (des) construção: narrativas escalares sobre desenvolvimento territorial rural. 2006. Tese (Doutorado em Geografia) -Programa de Pósgraduação em Geografia da Faculdade de Ciências e Tecnologia da Universidade Estadual Paulista, campus de Presidente Prudente.

KUDLAVICZ, Mieceslau. Dinâmica agrária e a territorialização do complexo celulose/papel na microrregião de Três Lagoas. 2010. Dissertação (Mestrado em Geografia). UFMS.Três Lagoas.177 p.

KUDLAVIZC, Mieceslau; ALMEIDA, Rosemeire Aparecida de. Em tempos de "privatização" da reforma agrária, a necessária práxis do bem comum. BOLETIM DATALUTA, Artigo do mês de: fevereiro de 2014. Disponível em:

<http://www2.fct.unesp.br/nera/artigodomes/2artigodomes_2014.pdf/>. Acesso em: 25 de Maio de 2014. 
MARQUES, Marta, I, M. A atualidade do uso do conceito de camponês. Revista NERA. Presidente Prudente. 2008. p.58-67.

MOURA, Margarida M. Camponeses. São Paulo: Ática, 1986.

OLIVEIRA, Ariovaldo Umbelino de. A agricultura camponesa no Brasil. São Paulo: Contexto, 1991.

Barbárie e modernidade: as transformações no campo e o agronegócio no Brasil.

Revista Terra Livre, São Paulo: AGB, ano 19, v. 2, n. 21, p. 113-156, jul./dez., 2003. .Geografia agrária: perspectivas no início do século XXI. In: OLIVEIRA, Ariovaldo U. de; MARQUES, Marta Inês Medeiros (Org.). O campo no século XXI: território de vida, de luta e de construção da justiça social. São Paulo: Casa amarela; Paz e Terra, 2004, p.27-64.

A geografia e os movimentos sociais. São Paulo: USP (digitado), 2007.

Agricultura e Indústria no Brasil. Campo-Território: revista de geografia agrária, v.5, n.10, p. 5-64, ago. 2010.

. A mundialização da agricultura brasileira. Actas: XII Colóquios de Geocrítica. Disponível em:<http://www.ub.edu/geocrit/coloquio2012/actas/14-A-Oliveira.pdf >. 2012. Acesso em: 22 fev. 2014.

OLIVEIRA, Alexandra Maria de. A política de Contra-Reforma Agrária do Banco Mundial no Ceará. Revista GEOUSP - Espaço e Tempo, São Paulo, no 19, pp. 151-175, 2006. Disponível em: <http://www.revistas.usp.br/geousp/article/view/73996/>. Acesso em: 20 de Setembro de 2013.

PAULINO, Eliane Tomiasi; ALMEIDA, Rosemeire Aparecida. Terra e território: a questão camponesa no capitalismo. São Paulo: Expressão Popular, 2010.

SÃO MIGUEL, Angélica Estigarribia. Alterações no Uso e Cobertura da Terra em Decorrência da Expansão do Cultivo de Eucalipto nas Microrregiões de Três Lagoas/MS e Paranaíba/MS, nos Anos de 2000, 2008 e 2014. 2015. 131 f. Dissertação (Mestre em Geografia). Programa de Pós Graduação- Mestrado em Geografia da Universidade Federal de Mato Grosso do Sul. Três Lagoas.

SHANIN, Teodor. Lições Camponesas. In: PAULINO, Eliane Tomiasi., FABRINI, João Edmilson (Orgs). Campesinato e territórios em disputa. São Paulo: Expressão Popular, 2008.

SILVA, Mariele de Oliveira. A (Re)criação do Campesinato em Cáceres/MT e no Contexto de Expansão Territorial do Agronegócio em Três Lagoas e Selvíria em Mato Grosso Do Sul._2014. 211 f. Dissertação (Mestre em Geografia). Programa de Pós Graduação- Mestrado em Geografia da Universidade Federal de Mato Grosso do Sul. Três Lagoas. 
SILVA, José Graziano da. O novo rural brasileiro. Campinas/SP: UNICAMP; INSTITUTO DE ECONOMIA, 1999. (Coleção Pesquisas, 1).

THOMAZ JUNIOR, Antonio. O agrohidronegócio no centro das disputas territoriais e de classe no Brasil do século XXI. Campo-território: revista de geografia agrária, v.5, n.10, p. 92-122, ago. 2010.

\section{Autores}

Danilo Souza Melo - Possui Graduação e Mestrado em Geografia pela Universidade Federal de Mato Grosso do Sul (UFMS). Atualmente é Assessor Territorial no Núcleo de Extensão e Desenvolvimento Territorial (NEDET) no Território Rural do Bolsão/MS.

Mariele de Oliveira Silva - Possui Graduação e Mestrado em Geografia pela Universidade Federal de Mato Grosso do Sul (UFMS). Atualmente é doutoranda em Geografia na Universidade Estadual de Londrina (UEL).

Artigo recebido em: 30 de julho de 2016

Artigo Aceito em: 17 de setembro de 2017 